\title{
Crisis management during anaesthesia: problems associated with drug administration during anaesthesia
}

\author{
A D Paix, M F Bullock, W B Runciman, J A Williamson
}

Qual Saf Health Care 2005;14:e15 (http://www.qshc.com/cgi/content/full/14/3/e15). doi: 10.1136/qshc.2002.004119

See end of article for authors' affiliations .....................

Correspondence to: Professor W B Runciman, President, Australian Patient Safety Foundation GPO Box 400, Adelaide, South Australia 5001 Australia; research@apsf. net.au

Accepted 12 January 2005
Background: Modern anaesthetic practice relies upon the administration of a wide range of potent drugs given by a variety of routes, at times in haste or under conditions of stress. Problems associated with drug administration make up the largest group of incidents reported during anaesthesia, with outcomes including major morbidity and death. It was decided to examine the role of a structured approach to the diagnosis and management of drug problems under anaesthesia.

Objectives: To examine the role of a previously described core algorithm "COVER ABCD-A SWIFT $\mathrm{CHECK}^{\prime \prime}$, supplemented by a specific sub-algorithm for drug problems, in the detection and management of drug problems occurring in association with anaesthesia.

Methods: The potential performance of this structured approach for the relevant incidents among the first 4000 incidents reported to the Australian Incident Monitoring Study (AIMS) was compared with the actual performances as reported by the anaesthetists involved.

Results: Among the first 4000 reports received by AIMS there were 1199 reports which detailed 1361 incidents involving the use of drugs. Contributing factors named included errors of judgement $(20 \%)$, lack of attention (17\%), and drugs deemed to have been given in haste. Major morbidity or prolonged stay ensued in over one quarter of reports and 15 patients (1.25\%) died. Drug overdose, side effects, and allergic reactions accounted for the majority of serious outcomes.

Conclusion: It was judged that the use of the COVER-ABCD algorithm during the course of an anaesthetic, properly applied, would prevent many drug related incidents from occurring. The sub-algorithm presented here provides a systematic framework for detecting the causes of drug related incidents.
M odern anaesthetic practice relies upon the administration of a wide range of (usually) potent drugs given by a variety of routes, at times in haste or under conditions of stress. The incidence of medication errors rises markedly with polypharmacy. ${ }^{1}$ Pharmacological incidents were the most commonly reported problem in the first 4000 incidents reported to the Australian Incident Monitoring Study (AIMS), constituting 30\% of all reports. ${ }^{2}$

A previously published paper by the AIMS group confined itself to the "wrong" drug problem, concluding that syringe swaps of labelled drugs was the most common incident, ${ }^{3}$ usually resulting from a "slip" - this being the result of "absent mindedness". ${ }^{4}$ A number of preventative strategies were proposed, including checking and rechecking of all ampoules, drawing up and labelling of one drug at a time, and supplying colour coded ampoules and syringes-for example, the use of a syringe with a red plunger for relaxants. ${ }^{5}$

In 1993 a "core" crisis management algorithm represented by the mnemonic COVER ABCD-A SWIFT CHECK (the AB precedes COVER for the non-intubated patient) was proposed as the basis for a systematic approach to crisis management during anaesthesia where it is not immediately obvious what should be done or when actions taken have failed to remedy the situation. ${ }^{6}$ This was validated against the first 2000 incidents reported to AIMS. AIMS is an ongoing study which involves the voluntary anonymous reporting of any unintended incident which reduced or could have reduced the safety margin for a patient. ${ }^{2}$

It was concluded that, if this algorithm had been correctly applied, a functional diagnosis would have been reached within 40-60 seconds in 99\% of applicable incidents and the learned sequence of actions represented by the COVER portion would have led to appropriate steps being taken to handle the $60 \%$ of problems relevant to this portion of the algorithm. ${ }^{6}$ However, this study also showed that the $40 \%$ of problems represented by the remainder of the algorithm ABCD-A SWIFT CHECK were not always promptly diagnosed or appropriately managed. ${ }^{267}$ It was decided that it would be useful, for these remaining problems, to develop a set of subalgorithms in an easy-to-use crisis management manual. ${ }^{8}$ This study reports on the potential place of the COVER ABCD-A SWIFT CHECK algorithm in the diagnosis and initial management of pharmacological errors, provides an outline of a specific crisis management sub-algorithm for drug associated incidents during anaesthesia, and examines the potential value of using this structured approach.

\section{METHODS}

Of the first 4000 incidents reported to AIMS, those which made reference to drug incidents were extracted and analysed for relevance, presenting features, causes, diagnosis and outcome. Those due to vascular access problems and those resulting in (or with the potential for) awareness are included but are dealt with in greater depth elsewhere in this set of articles. ${ }^{90}$ For completeness, problems arising from the administration of blood and its products are also included in the analysis.

The COVER ABCD-A SWIFT CHECK algorithm, described elsewhere in this series of articles, ${ }^{8}$ was applied to each relevant report to determine the stages at which the problem might have been diagnosed and to confirm that activating the COVER portion would have led to appropriate initial steps being taken. As drug problems are not completely dealt with by this algorithm, a specific sub-algorithm was developed (see fig 1) and its putative effectiveness was tested against the reports. How this was done is described elsewhere in this series of articles. ${ }^{8}$ The potential value of this structured approach-that is, the application of COVER ABCD-A SWIFT CHECK to the diagnosis and initial management of these 


\section{DRUGS/VASCULAR ACCESS}

\section{EMERGENCY CHECK}

Review all ampoules/syringes/bags/burettes/cassettes (1)*

Review all drug labels

Systematically review all vascular access equipment (5)

Work from fluid source/cannula/skin interface (4)

Check vehicles/dilutions/rates/routes are correct

Correlate doses with effects

\section{ALWAYS CONSIDER}

Wrong patient

Wrong drug (6)

Ampoule or syringe swap

Known allergy

Right drug (6)

Wrong dose/rate (2)

Wrong diluent/dilution

Wrong time

Wrong route/site

Failure of intended delivery

Malpositioned cannula tip (4)

Bag/syringe/burette empty

Cannula disconnected/blocked/kinked

Line disconnected/blocked/kinked

Back flow (up a Y-piece)

Unintended delivery (6)

Drug flushed from dead space (7)

Drip/pump delivering drug inadvertently (8)

Flushing syringe containing drug

Someone else giving a drug (3)

Check for any recognized cannulae in situ (8)

\section{BEWARE}

Any syringe containing relaxant

Haematoma/extravasation

Inadvertent intra-arterial placement

Pneumothorax, haemothorax, hydrothorax

Nerve damage

Dysrhythmias (cannula tip in heart)

Cannula dead space

The sub-algorithm forms a facing page of the

Crisis Management Manual16.

* Numbers in brackets refer to Notes in the right hand panel.

\section{DRUGS}

(1) Problems with drug administration comprised $30 \%$ of all 4,000 reports to AIMS. Incidence of errors rises markedly with polypharmacy.

(2) Major morbidity in $25 \%$ of drug reports. Death in $1.25 \%$. Causes of major morbidity - drug overdosage $33 \%$; side-effects $20 \%$; allergic reactions $17 \%$.

(3) Contributory factors:

- error of judgement $13 \%$

- inattention $11 \%$

- haste $10 \%$

- communication problem $9 \%$

- drug label problem 5\%

- fatigue $3 \%$

\section{VASCULAR ACCESS}

(4) $51 \%$ of the 128 vascular access cases involved a fault at the catheter/skin interface. In 15\% of these the cannula was inserted by someone other than the anaesthesiologist. $18 \%$ involved central venous lines.

(5) Incorrect manufacture or assembly of arterial/central/peripheral lines $-8 \%$. Disconnection resulting in unrecognized blood loss $-6 \%$.

(6) Errors included:

- Connection of wrong drug infusion pump - 3\%

- Over/under dosage fluid/drugs - $2 \%$

- Drug precipitation in the line dead space - $2 \%$

- Anaphylaxis to infusions - $2 \%$.

(7) Suxamethonium remaining in the dead space caused late paralysis upon subsequent line flushing in 6 case reports.

(8) Unrecognized cannulae may be the source of disconnections or be the route of an unknown delivery of drugs/fluids.

These notes comprise a reverse side of a page of the

Crisis Management Manual ${ }^{16}$.

Figure 1 Drugs/vascular access.

problems, followed by the application of the sub-algorithm for drug problems - was assessed in the light of the AIMS reports by comparing its potential effectiveness for each incident with that of the actual management as recorded in each report.

\section{RESULTS}

Among the first 4000 AIMS reports there were 1199 reports involving drug incidents (30\%). A total of 1361 drug related incidents were reported as some incidents involved more than one drug problem. Table 1 summarises the major categories of incidents. The most common problems were overdosage $(20 \%)$ and giving the wrong drug (17\%).

Many factors were judged to have contributed to the incidents-most commonly, errors of judgement, $(n=240$, $20 \%)$; inattention $(\mathrm{n}=211,18 \%)$; drugs given in haste $(\mathrm{n}=200,17 \%)$; and problems with communication $(\mathrm{n}=163,14 \%)$. Further details are given in table 2 .

Outcomes from these incidents varied from no change through to death. More than one outcome occurred in a number of reports. For instance, patients suffering major morbidity often progressed to a prolonged hospital stay or

\begin{tabular}{|lc|}
\hline $\begin{array}{l}\text { Table 1 Type of pharmacological incident } \\
(\mathrm{n}=1361)\end{array}$ \\
\hline Incident & No \\
\hline Overdosage & 273 \\
Wrong drug & 236 \\
Side effect & 198 \\
Underdosage & 145 \\
Allergy phenomenon & 109 \\
Inappropriate drug & 94 \\
Interaction & 38 \\
Contamination & 7 \\
Other drug incident & $261^{*}$ \\
\hline *This includes wrong patient, wrong route, wrong timing, \\
wrong rate. \\
\hline
\end{tabular}

unplanned high dependency admission. Table 3 provides a summary of the outcomes.

Fifteen deaths were reported in this series (table 4). The most commonly reported problem in this group was related 


\begin{tabular}{|lc|}
\hline $\begin{array}{l}\text { Table } 2 \text { Factors contributing to the incident } \\
(\mathrm{n}=1911)^{*}\end{array}$ \\
\hline Factors & No \\
\hline Error of judgement & 240 \\
Inattention & 211 \\
Haste & 200 \\
Communication problem & 163 \\
Fault of technique & 132 \\
Inexperience & 126 \\
Failure to check equipment & 98 \\
Drug label & 96 \\
Preoperative patient assessment & 75 \\
inadequate/incorrect & \\
Fatigue & 59 \\
Preoperative patient preparation & 55 \\
inadequate/incorrect & \\
Distraction & 54 \\
Unfamiliar environment or equipment & 35 \\
Inadequate assistance & 26 \\
Monitor problem & 26 \\
Pressure to proceed & 22 \\
Surgical team contribution & 22 \\
Relief anaesthetist or staff change & 19 \\
Sick patient & 14 \\
Lack of monitor & 13 \\
Lack of facility & 9 \\
Sick anaesthetist & 6 \\
Other equipment problems & 46 \\
Other stress & 27 \\
All other factors & 137 \\
\hline *More than one factor was nominated in some reports. \\
\hline
\end{tabular}

to the administration of intrathecal local anaesthetics (four cases). All involved relatively small doses of local anaesthetic to frail elderly patients undergoing urgent or emergency surgery. Three cases presented as hypotension and/or bradycardia and the fourth as a high spinal with initial respiratory embarrassment, progressing to cardiorespiratory arrest. In retrospect, it was considered that the first three patients were inadequately resuscitated before administration of the anaesthetic.

There were three reports involving fatal side effects when drugs were given by routes other than intrathecal, including one case in which, unknown to the anaesthetist, a drug was administered by a surgeon. There were two reports of death in association with blood products, one involving a patient with unusual antibodies and the other an error in the transfusion laboratory with transposition of labels of two patients being cross matched at the same time. Other causes were anaphylactic reactions in two reports, drug overdosage in two reports, and giving the wrong drug in two reports. All these fatal incidents may be considered a result of errors ${ }^{4}$ with the exception of the two deaths following anaphylaxis. The majority of drug related deaths in this series were therefore potentially avoidable.

Drug overdosage (33\%), drug side effects $(20 \%)$, and allergic reactions to drugs $(17 \%)$ accounted for most

\begin{tabular}{|lc}
\hline $\begin{array}{lc}\text { Table } 3 \text { Outcomes following drug incidents } \\
(\mathrm{n}=1243)^{*}\end{array}$ \\
\hline Outcomes & No \\
\hline No change & 568 \\
Minor physiological change/minor morbidity & 288 \\
Major physiological change/major morbidity & 212 \\
Prolonged stay & 65 \\
Unplanned high dependency care & 56 \\
Awareness & 39 \\
Death & 15 \\
\hline \multirow{2}{*}{ *More than one outcome was nominated in some reports. }
\end{tabular}

\section{Table 4 Causes of death $(n=15)$}

\begin{tabular}{|c|c|c|}
\hline Cause & No & Comments \\
\hline $\begin{array}{l}\text { Sequelae of intrathecal local } \\
\text { anaesthetic administration }\end{array}$ & 4 & $\begin{array}{l}3 \text { cases of hypotension and/ } \\
\text { or bradycardia }\end{array}$ \\
\hline Drug side effects* & 3 & \\
\hline Reaction to blood products & 2 & $\begin{array}{l}1 \text { report of blood mislabelling } \\
\text { by transfusion }\end{array}$ \\
\hline Allergy/anaphylaxis & 2 & 1 to antibiotic, 1 to protamine \\
\hline Drug overdose & 2 & $\begin{array}{l}\text { Involving use of propofol in } \\
\text { elderly patients }\end{array}$ \\
\hline Wrong drug & 2 & $\begin{array}{l}\text { Air instead of } 100 \% \text { oxygen in } \\
1 \text { case }\end{array}$ \\
\hline
\end{tabular}

incidents resulting in major morbidity in this series (table 5). Not surprisingly, management of this group of problems often resulted in ongoing high dependency care and/or an abnormally prolonged hospital stay.

\section{DISCUSSION}

Problems related to the administration of drugs made up $1199(30 \%)$ of the first 4000 reports received by AIMS. Outcomes ranged from no change $(47 \%)$ through to death in 15 reports $(1.25 \%)$. Thus, drug related problems in this series are common and many had serious consequences. The majority may be regarded as potentially preventable, however difficult in clinical practice this may be to achieve.

Adverse drug events are common throughout medical practice and may result in serious consequences. ${ }^{11}{ }^{12}$ Problems frequently arise as a result of complex chains of events, so robust systems must be in place to minimise or eliminate such errors. A recent project reported significant reductions in adverse drug events $(27 \%)$ and a concurrent rise in error detection and prevention ( $12 \%$ ) resulting from changes in the systems in place by which drugs were administered. ${ }^{13}$ These improvements were sustained. An integrated drug administration system specifically for use in anaesthesia has been developed, also aimed at preventing drug administration errors by reducing the number of steps, automating aspects of the process, and rendering them more transparent. ${ }^{14} 15$

In the course of anaesthetic practice, where drugs are often given during periods of haste and stress, the potential for error remains great. Problems may result from several broad groups of errors, starting with drawing up and labelling of drugs in syringes, through to administration via any apparatus and any route; the pharmacological effects and side effects of the drug may also cause problems. Because drug administration during anaesthesia is commonly by the intravenous route, this paper should be regarded as a companion to the paper dealing with problems with vascular access which is presented elsewhere in this series. ${ }^{9}$

Incidents arising during the course of an anaesthetic may frequently have a component attributable to a drug error, interaction, effect or side effect. The use of COVER in the

\begin{tabular}{|lc|}
\hline Table $5 \quad$ Causes of major morbidity $(\mathrm{n}=212)$ \\
\hline Type of incident & No \\
\hline Drug overdosage & 71 \\
Drug side effect & 43 \\
Allergy/anaphylaxis & 37 \\
Drug underdosage & 16 \\
Inappropriate drug & 15 \\
Wrong drug & 14 \\
Drug interaction & 12 \\
Other & 4 \\
\hline
\end{tabular}




\section{Key messages}

- From the first 4000 incidents reported to AIMS, 1361 incidents were identified within 1199 reports (30\%) that involved drug related incidents.

- The most common pharmacological incidents were overdosage (273 incidents), wrong drug (236 incidents), side effect (198 incidents), underdosage (145 incidents), and allergic manifestations (109 incidents).

- The most common contributing factors reported were error of judgement (240 incidents), inattention (211 incidents), haste (200 incidents), communication problem (163 incidents), and technical fault (132 incidents).

- The outcome from 1243 analysable incidents ranged from no change (568 cases) through major physiological change/major morbidity (212 cases) to awareness (39 cases) and death (15 cases, $1.25 \%$ ).

- The most common cause of death $(n=4)$ was sequelae of intrathecal administration of a local anaesthetic. Two other fatal cases involved anaphylaxis.

- The most common cause of major morbidity was drug overdosage $(n=71)$ and drug side effects $(n=43)$.

- The common occurrence of incidents in anaesthetic practice relating to drug administration (or nonadministration) necessitates that this always be considered as a possible cause of a problem developing during the conduct of anaesthesia.

- The specific sub-algorithm presented in this paper provides a systematic framework for identifying problems arising from drug administration. The sequelae of such incidents may require other specific crisis management sub-algorithms described in this series of papers to be invoked.

SCAN and CHECK modes should identify the majority of sequelae from such incidents but, unless a drug (or blood product) or vascular access problem is considered as part of the ABCD sequence and specifically excluded, the cause of the problem may be difficult to determine and therefore to correct. A sub-algorithm is presented in fig 1 that provides a systematic framework to locate and treat the common causes of drug and vascular access problems. A "geographical" approach to aid in the detection of vascular access problems is presented elsewhere in this series. ${ }^{9}$

The corrective strategies required will depend upon the sequelae and range from simple drug cessation or reinstitution through to treatment of specific crisis situations that result from or are associated with the medication error.

In conclusion, incidents relating to the administration (or unintended non-administration) of drugs are very common in anaesthetic practice. A myriad of presentations may ensue. A drug problem or medication error should always be considered as a possible cause of any incident arising in association with the conduct of anaesthesia. The use of COVER ABCD in the SCAN and CHECK modes regularly during the course of an anaesthetic should prevent many incidents from occurring and allow for early detection of evolving problems. The sub-algorithm presented here provides a systematic framework for identifying problems arising from drug administration. The sequelae of drug related incidents may require other specific crisis management sub-algorithms presented elsewhere in this series of papers to be invoked.
Finally, it is important that a full explanation of what happened be given to the patient, that the event and the results of any tests should be documented in the anaesthetic record and, if appropriate, that the patient be given a letter to warn future anaesthetists. A permanent warning bracelet may be required for the patient. If a particular precipitating event was significant or a particular action was useful in resolving the crisis, this should be clearly explained and documented.

\section{ACKNOWLEDGEMENTS}

The authors would like to thank all the anaesthetists in Australia and New Zealand who contributed to the 4000 incident reports upon which this and the other 24 papers in the Crisis Management Series are based. The coordinators of the project also thank Liz Brown for preparing the draft of the original Crisis Management Manual; Loretta Smyth for typing; Monika Bullock RN for earlier coding and classifying of data; Dr Charles Bradfield for the electronic version of the algorithms; Dr Klee Benveniste for literature research; and Drs Klee Benveniste, Michal Kluger, John Williamson and Andrew Paix for editing and checking manuscripts.

\section{Authors' affiliations}

A D Paix, Consultant Anaesthetist, Princess Royal University Hospital, Orpington, Kent, UK

M F Bullock, Anaesthetic Registered Nurse, Royal Adelaide Hospital, Adelaide, South Australia, Australia

W B Runciman, Professor and Head, Department of Anaesthesia and Intensive Care, University of Adelaide and Royal Adelaide Hospital, Adelaide, South Australia, Australia

J A Williamson, Consultant Specialist, Australian Patient Safety Foundation and Visiting Research Fellow, University of Adelaide and Royal Adelaide Hospital, Adelaide, South Australia, Australia

This study was coordinated by The Australian Patient Safety Foundation, GPO Box 400, Adelaide, South Australia 5001, Australia.

\section{REFERENCES}

1 Gilbert AL, Roughead EE, Beilby J, et al. Collaborative medication management services: improving patient care. Med J Aust 2002; 177: 189-92.

2 Webb RK, Currie M, Morgan CA, et al. The Australian Incident Monitoring Study: an analysis of 2000 incident reports. Anaesth Intensive Care 1993;21:520-8.

3 Currie M, Mackay P, Morgan C, et al. The Australian Incident Monitoring Study. The "wrong drug" problem in anaesthesia: an analysis of 2000 incident reports, Anaesth Intensive Care 1993;21:596-601.

4 Runciman WB, Sellen A, Webb RK, et al. Errors, incidents and accidents in anaesthetic practice. Anaesth Intensive Care 1993;21:506-19.

5 Russell WJ. Getting into the red: a strategic step for safety. Qual Saf Health Care 2002;11:107.

6 Runciman WB, Webb RK, Klepper ID, et al. Crisis management: validation of an algorithm by analysis of 2000 incident reports. Anaesth Intensive Care 1993;21:579-92.

7 Webb RK, van der Walt JH, Runciman WB, et al. Which monitor? An analysis of 2000 incident reports. Anaesth Intensive Care 1993;21:520-8.

8 Runciman WB, Kluger MT, Morris RW, et al. Crisis management during anaesthesia: the development of an anaesthetic crisis management manual. Qual Saf Health Care 2005; 14:e1.

9 Singleton RJ, Kinnear $S$, Currie $M$, et al. Crisis management during anaesthesia: vascular access problems. Qual Saf Health Care 2005; 14:e20.

10 Osborne GA, Bacon AK, Runciman WB, et al. Crisis management during anaesthesia: awareness. Qual Saf Health Care 2005; 14:e16.

11 Silver MP, Antonow JA. Reducing medication errors in hospitals: a peer review organization collaboration. Jt Comm J Qual Improv 2000;26:332-40.

12 Runciman WB, Roughead EE, Semple SJ, et al. Adverse drug events and medication errors in Australia. Int $J$ Qual Health Care 2003; 15(Suppl 1):i49-59.

13 Leape LL, Kabcenell Al, Gandhi TK, et al. Reducing adverse drug events: lessons from a breakthrough series collaborative. Jt Comm J Qual Improv 2000;26:321-31.

14 Webster CS, Merry AF, Gander PH, et al. A prospective, randomised clinical evaluation of a new safety-orientated injectable drug administration system in comparison with conventional methods. Anaesthesia 2004;59:80-7.

15 Merry AF, Webster CS, Mathew DJ. A new, safety-oriented, integrated drug administration and automated anesthesia record system. Anesth Analg 2001;93:385-90.

16 Australian Patient Safety Foundation. Crisis Management Manual: COVER $A B C D$ A SWIFT CHECK. Adelaide: Australian Patient Safety Foundation, 1996, 74 pp. Available at http://www.apsf.net.au/anaesthesia.htm (accessed 6 September 2004). 